\title{
Steroidal Alkaloid Glycosides, Esculeosides C and D, from the Ripe Fruit of Cherry Tomato
}

\author{
Masateru Ono, ${ }^{*, a}$ Yuuki Takara, ${ }^{a}$ Masamichi Egami, ${ }^{b}$ Koichi Uranaka, ${ }^{b}$ Hitoshi Yoshimitsu, ${ }^{c}$ \\ Sayaka Matsushita, ${ }^{d}$ Yukio Fujiwara,${ }^{d}$ Tsuyoshi IkedA,${ }^{d}$ and Toshihiro Nohara ${ }^{d}$ \\ ${ }^{a}$ School of Agriculture, Kyushu Tokai University; 5435 Minamiaso, Aso, Kumamoto 869-1404, Japan: ${ }^{b}$ Milieu Laboratory \\ \& Co.; 18-1 Suizenji, Kumamoto 862-0950, Japan: ${ }^{c}$ Faculty of Pharmaceutical Sciences, Sojo University; 4-22-1 Ikeda, \\ Kumamoto 860-0082, Japan: and ${ }^{d}$ Faculty of Medical and Pharmaceutical Sciences, Kumamoto University; 5-1 Oe- \\ honmachi, Kumamoto 862-0973, Japan. Received August 5, 2005; accepted October 28, 2005
}

Two new steroidal alkaloid glycosides, esculeosides $C$ and $D$, have been isolated from the ripe fruit of Cherry tomato [Lycopersicon esculentum var. cerasiforme (DunAL) ALEF.], along with three known steroidal alkaloid glycosides, esculeoside A, esculeoiside B, and lycoperoside $G$. Their chemical structures were determined on the basis of spectroscopic data.

Key words Lycopersicon esculentum; Cherry tomato; steroidal alkaloid glycoside; esculeoside; pregnane; solanocapsine

In previous papers, we reported the isolation and structural elucidation of a major steroidal alkaloid glycoside, esculeoside A, from the ripe fruit of Cherry tomato [Lycopersicon esculentum var. cerasiforme (DuNAL) ALEF.] and pink colortype tomato (Lycopersicon esculentum, Momotaro), ${ }^{1,2)}$ a major solanocapsine-type glycoside, esculeoside B, from the ripe fruit of red color-type tomato (Lycopersicon esculentum, Italian San Marzano), ${ }^{2)}$ and a pregnane glycoside, tomatopregnane, from the overripe fruit of Cherry tomato. ${ }^{3)}$ The present paper describes the isolation and structural characterization of two new steroidal alkaloid glycosides $(\mathbf{1}, \mathbf{2})$, along with three known steroidal alkaloid glycosides (3-5) from the ripe fruit of Cherry tomato.

The ripe fruit of Cherry tomato was smashed and then centrifuged. The supernatant was successively subjected to Diaion HP20, Chromatorex NH, and silica gel column chromatographies, as well as HPLC on ODS, to afford five steroidal alkaloid glycosides $(\mathbf{1}-\mathbf{5})$.

Compounds $\mathbf{3}-\mathbf{5}$ were identified as esculeoside A (3), ${ }^{1,2)}$ esculeoside B (4), ${ }^{2)}$ and lycoperoside G (5), ${ }^{4)}$ respectively, based on their physical and spectral data.

Compound 1, tentatively designated esculeoside $\mathrm{C}$, was obtained as an amorphous powder, $[\alpha]_{\mathrm{D}}-56.7^{\circ}$ (pyridine). The negative FAB-MS and positive FAB-MS exhibited an $[\mathrm{M}-\mathrm{H}]^{-}$ion peak at $\mathrm{m} / z 1254$ and an $[\mathrm{M}+\mathrm{Na}]^{+}$ion peak at $\mathrm{m} / \mathrm{z} 1278$, respectively. The molecular formula of $\mathbf{1}$ was determined to be $\mathrm{C}_{57} \mathrm{H}_{93} \mathrm{NO}_{29}$ by high-resolution (HR) positive FAB-MS. The ${ }^{1} \mathrm{H}-\mathrm{NMR}$ spectrum of $\mathbf{1}$ showed signals due to three tertiary methyl groups $(\delta 1.72,0.85,0.81)$, one methoxyl group $(\delta 3.22)$, and five anomeric protons $[\delta 5.58$ $(\mathrm{d}, J=7.5 \mathrm{~Hz}), 5.25$ (d, $J=8.0 \mathrm{~Hz}), 5.21(\mathrm{~d}, J=8.0 \mathrm{~Hz}), 4.90$ $(\mathrm{d}, J=8.0 \mathrm{~Hz}), 4.83$ (d, $J=8.0 \mathrm{~Hz})]$. The ${ }^{13} \mathrm{C}-\mathrm{NMR}$ spectrum of 1 was similar to that of 4 ; in particular, the signals due to the sugar moiety were almost superimposable, although signals due to one methoxyl carbon ( $\delta 47.3)$, one oxygen-bearing quaternary carbon ( $\delta$ 73.4), and one olefinic carbon ( $\delta$ 165.4) appeared and signals due to one methine carbon and one nitrogen-bearing methine carbon disappeared. These NMR signals were assigned in detail with the aid of ${ }^{1} \mathrm{H}-{ }^{1} \mathrm{H}$ correlation spectroscopy (COSY), heteronuclear multiple
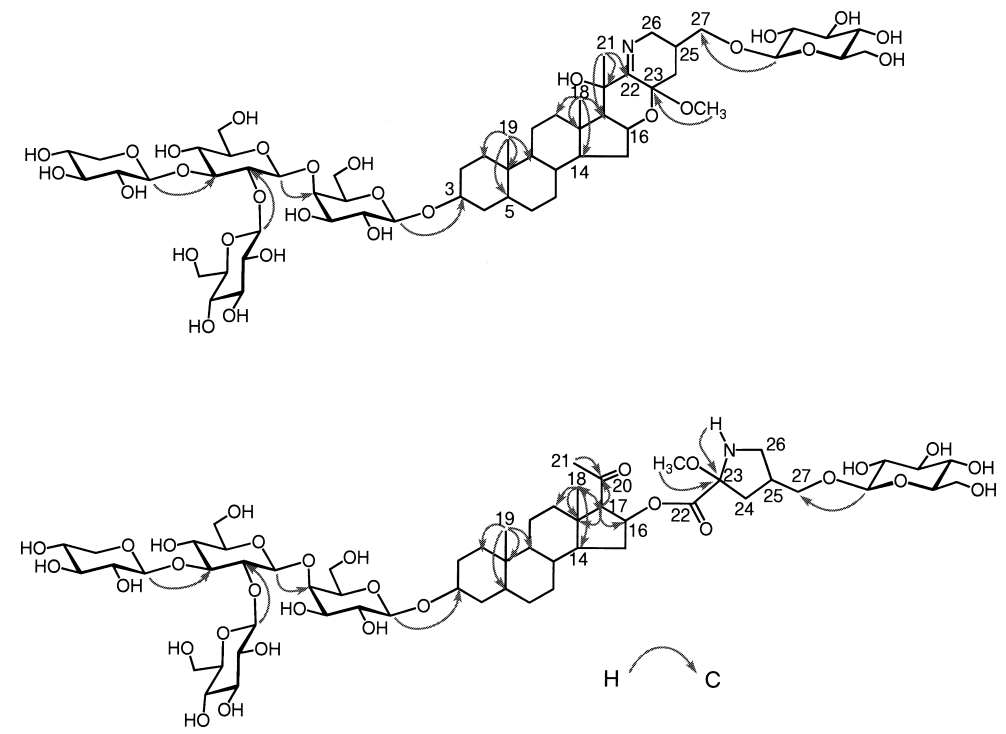

Fig. 1. ${ }^{1} \mathrm{H}-{ }^{13} \mathrm{C}$ Long-Range Correlations Observed for $\mathbf{1}$ and $\mathbf{2}$ in the HMBC Spectra (in Pyridine- $d_{5}, 500 \mathrm{MHz}$ ) 
quantum coherence (HMQC), and heteronuclear multiple bond correlation (HMBC) techniques, and the planar structure of 1 was determined as illustrated in Fig. 1. The stereostructure was defined on the basis of nuclear Overhauser and exchange spectroscopy (NOESY) spectra and coupling constant values of the signals due to equatorial proton $(\mathrm{Hb}-$ 26) at C-26. The key NOEs were observed between H-16 and $\mathrm{OCH}_{3}$, between $\mathrm{H}-16$ and $\mathrm{H}-17$, and between $\mathrm{H}_{3}-18$ and $\mathrm{H}_{3}-$ 21. Furthermore, the coupling constant values of the signal due to $\mathrm{Hb}-26[\delta 3.46(\mathrm{dd}, J=11.0,18.5 \mathrm{~Hz})]$ were superimposable on those of 22,26-epimino-16 $\beta, 23$-epoxy-23 $\alpha$-ethoxy$5 \alpha, 25 \alpha$ H-cholest- $22(N)$-ene-3 $\beta, 20 \alpha$-diol (6), which was isolated from the root of tomato stock by Nagaoka et al. ${ }^{5)}$ From these data, the configurations at C-16, C-17, C-20, C-23, and C-25 were determined to be $S, R, S, R$, and $S$, respectively. Consequently, 1 was defined as $3-O-\beta$-lycotetraosyl $(5 S, 25 S)$ $22,26$-epimino-16 $\beta, 23$-epoxy-23 $\alpha$-methoxy-22( $N)$-ene$3 \beta, 20 \alpha, 27$-trihydroxycholestane $27-O-\beta$-D-glucopyranoside.

Compound 2 , tentatively designated esculeoside $\mathrm{D}$, was obtained as an amorphous powder, $[\alpha]_{\mathrm{D}}-20.7^{\circ}$ (pyridine), and showed an $[\mathrm{M}-\mathrm{H}]^{-}$ion peak at $\mathrm{m} / \mathrm{z} 1270$ in the negative FAB-MS and an $[\mathrm{M}+\mathrm{Na}]^{+}$ion peak at $\mathrm{m} / z 1294$ in the posi-

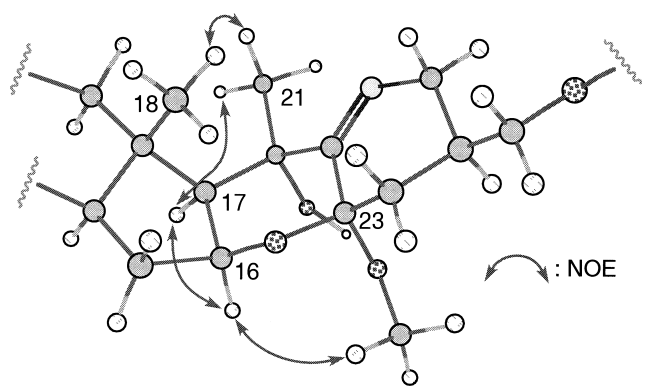

Fig. 2. Selected NOE Correlations Observed for $\mathbf{1}$ in the NOESY Spectrum (in Pyridine- $d_{5}, 500 \mathrm{MHz}$ ) tive FAB-MS. The HR positive FAB-MS showed the molecular formula of 2 to be $\mathrm{C}_{57} \mathrm{H}_{93} \mathrm{NO}_{30}$. In the ${ }^{1} \mathrm{H}-\mathrm{NMR}$ spectrum, the signals due to two tertiary methyl groups $(\delta 1.32,0.64)$, one acetyl group $(\delta 2.42)$, one methoxyl group $(\delta 3.46)$, one amino proton $(\delta 8.93)$, and five anomeric protons $[\delta 5.58(\mathrm{~d}$, $J=7.0 \mathrm{~Hz}), 5.25$ (d, $J=7.5 \mathrm{~Hz}), 5.21$ (d, $J=8.0 \mathrm{~Hz}), 4.90$ (d, $J=8.0 \mathrm{~Hz}), 4.87(\mathrm{~d}, J=8.0 \mathrm{~Hz})]$ were observed. The ${ }^{13} \mathrm{C}$ NMR spectrum of $\mathbf{2}$ gave 28 carbon signals for the aglycone moiety, including the signals due to one ketone carbonyl carbon $(\delta 207.0)$, one ester carbonyl carbon $(\delta 168.3)$, and one nitrogen- and oxygen-bearing carbon ( $\delta$ 96.9), and quite similar signals to those of $\mathbf{1}$ for the sugar moiety. These ${ }^{1} \mathrm{H}$ - and ${ }^{13} \mathrm{C}$-NMR signals were assigned in detail using techniques similar to those used for 1. The HMBC spectrum indicated correlations of the ketone carbonyl carbon with $\mathrm{H}-17$ and acetyl protons. Further, the signal due to $\mathrm{H}-16$ of $\mathrm{Ag}$ was subjected to acylation shift by $0.80 \mathrm{ppm}$ in comparison with that (in $\mathrm{CD}_{3} \mathrm{OD}$ ) of lycopersiconol $(7)^{6)}$ in the ${ }^{1} \mathrm{H}-\mathrm{NMR}$ spectrum. On the basis of the above findings, the planar structure of 2 was elucidated to be a pregnane glycoside, with a $\beta$-lycotetraosyl group at C-3, an alkaloid ester group at C-16, and a $\beta$-glucopyranosyl group at $\mathrm{C}-27$, as shown in Fig. 1 . The stereochemistry of C-16 and C-17 were determined by analysis of the coupling constant values of the signals due to $\mathrm{H}-16$ $[\delta 5.45(\mathrm{ddd}, J=7.5,7.5,7.5 \mathrm{~Hz})]$ and $\mathrm{H}-17[\delta 2.51(\mathrm{~d}, J=$ $7.5 \mathrm{~Hz})]$, which were similar to those of $16 \beta-[[(4 S)-5-(\beta-$ D-glucopyranosyloxy)-4-methyl-1-oxopentyl $]$ oxy $]-3 \beta$-[(O- $\alpha$ L-rhamnopyranosyl- $(1 \rightarrow 2)-O$-[ $\alpha$-L-rhamnopyranosyl- $(1 \rightarrow$ $3)]$ - $\beta$-D-glucopyranosyl)oxy]pregn-5-en-20-one $(8),{ }^{7)}$ in the ${ }^{1} \mathrm{H}-\mathrm{NMR}$ spectrum. The absolute configuration at C-26 was recognized to be $S$, since 2 was considered to be biosynthetically produced from 3. ${ }^{3}$ However, the configuration at C-23 has not been confirmed. Consequently, 2 was elucidated to be 3 - $O$ - $\beta$-lycotetraosyl $3 \beta, 16 \beta$-dihydroxy-5 $\alpha$-pregn-20-one 16 $O$ - $[(4 S)-2,5$-epimino-2-methoxy-4- $(\beta$-D-glucopyranosyloxy)methyl-pentanoic acid]-ester.
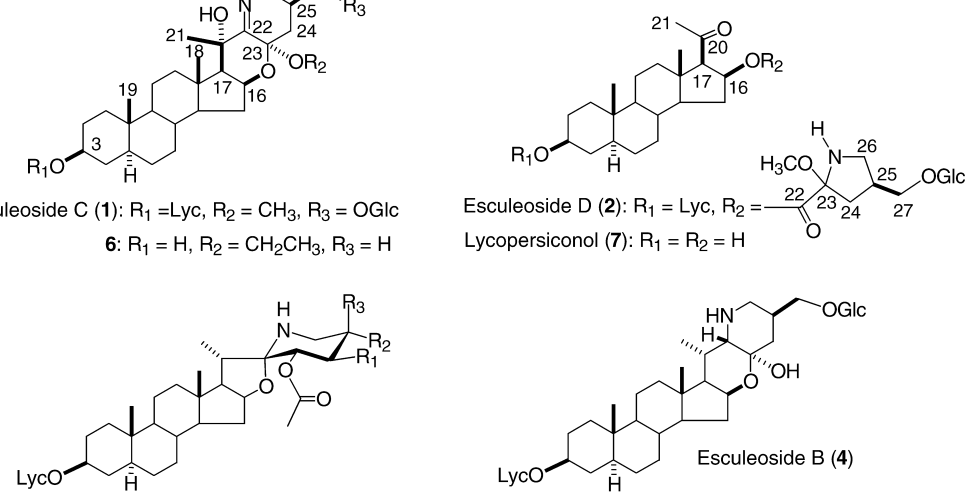

Esculeoside A (3): $\mathrm{R}_{1}=\mathrm{R}_{2}=\mathrm{H}, \mathrm{R}_{3}=\mathrm{CH}_{2} \mathrm{OGlc}$

Lycoperoside $G(5)$ : $R_{1}=$ OGlc, $R_{2}=C_{3}, R_{3}=H$

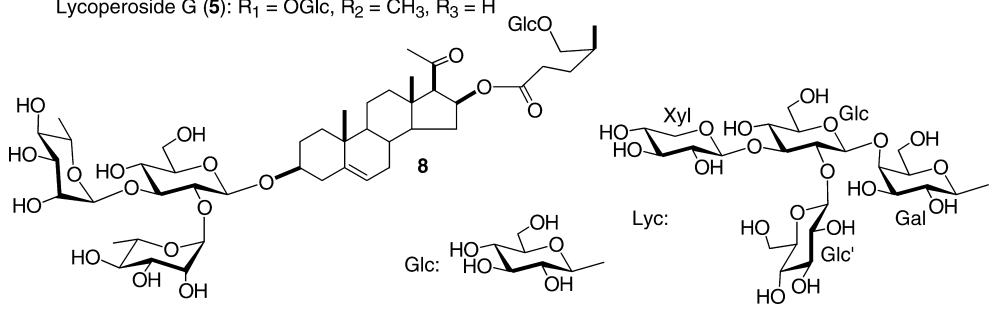

Fig. 3. Structures of $\mathbf{1}-\mathbf{8}$ 
Table $1 .{ }^{13} \mathrm{C}-\mathrm{NMR}$ Data for $\mathbf{1}$ and $\mathbf{2}$ (in Pyridine- $d_{5}, 125 \mathrm{MHz}$ )

\begin{tabular}{|c|c|c|c|c|c|}
\hline Position & 1 & 2 & Position & 1 & 2 \\
\hline 1 & 37.2 & 37.2 & Gal-1 & 102.6 & 102.4 \\
\hline 2 & 29.9 & 29.9 & Gal-2 & 73.2 & 73.2 \\
\hline 3 & $77.8^{a)}$ & $77.8^{a)}$ & Gal-3 & $75.7^{b)}$ & $75.7^{b)}$ \\
\hline 4 & 34.9 & 34.9 & Gal-4 & 79.9 & 79.9 \\
\hline 5 & 44.8 & 44.8 & Gal-5 & $75.2^{b)}$ & $75.1^{b)}$ \\
\hline 6 & 29.0 & 29.0 & Gal-6 & 60.7 & 60.7 \\
\hline 7 & 32.1 & 32.3 & Glc-1 & 105.1 & 105.1 \\
\hline 8 & 35.0 & 34.7 & Glc-2 & 81.3 & 81.3 \\
\hline 9 & 54.6 & 54.6 & Glc-3 & 86.9 & 86.9 \\
\hline 10 & 35.8 & 35.9 & Glc-4 & 70.8 & 70.8 \\
\hline 11 & 20.9 & 20.9 & Glc-5 & 77.5 & 77.4 \\
\hline 12 & 39.9 & 38.7 & Glc-6 & $62.9^{c)}$ & 62.6 \\
\hline 13 & 42.3 & 42.9 & Glc'-1 & 104.8 & 104.8 \\
\hline 14 & 54.9 & 54.1 & Glc'-2 & 76.2 & 76.2 \\
\hline 15 & 33.5 & 37.3 & Glc'-3 & $78.6^{d)}$ & $78.6^{c)}$ \\
\hline 16 & 70.5 & 74.0 & $\mathrm{Glc}^{\prime}-4$ & 71.1 & 71.1 \\
\hline 17 & 66.7 & 68.4 & Glc'-5 & $77.6^{a)}$ & $77.6^{a)}$ \\
\hline 18 & 13.3 & 15.1 & Glc'-6 & 62.6 & 63.0 \\
\hline 19 & 12.3 & 12.3 & Xyl-1 & 105.1 & 105.0 \\
\hline 20 & 73.4 & 207.0 & Xyl-2 & $75.4^{b)}$ & $75.1^{b)}$ \\
\hline 21 & 25.1 & 32.4 & Xyl-3 & $78.7^{d)}$ & $78.6^{c)}$ \\
\hline 22 & 165.4 & 168.3 & Xyl-4 & 70.5 & 70.5 \\
\hline 23 & 95.9 & 96.9 & Xyl-5 & 67.4 & 67.4 \\
\hline 24 & 31.7 & 35.9 & Glc"-1 & 105.0 & 105.0 \\
\hline 25 & 31.9 & 32.3 & Glc"-2 & 75.1 & 75.4 \\
\hline 26 & 54.1 & 44.5 & Glc"-3 & $78.7^{d)}$ & $78.7^{c)}$ \\
\hline 27 & 72.0 & 71.7 & Glc"-4 & 71.8 & 71.8 \\
\hline \multirow[t]{2}{*}{$\mathrm{OCH}_{3}$} & 47.3 & 50.9 & Glc"-5 & $78.6^{d)}$ & $78.7^{c)}$ \\
\hline & & & Glc" -6 & $63.0^{c)}$ & 63.0 \\
\hline
\end{tabular}

$\delta$ in ppm from TMS. $a-d$ ) Assignments may be interchanged. Gal, galactopyranosyl; Glc, glucopyranosyl; Xyl, xylopyranosyl.

\section{Experimental}

All the instruments and materials used were the same as those cited in a previous report, ${ }^{8)}$ unless otherwise specified.

Plant Material The fruit of Cherry tomato was collected in September 2004 at the orchard of Kyushu Tokai University, Kumamoto prefecture.

Extraction and Isolation The fresh ripe fruit of Cherry tomato ( $L$. esculentum var. ceraciforme) $(11.78 \mathrm{~kg})$ was smashed and then centrifuged. The supernatant was chromatographed over Diaion $\mathrm{HP} 20\left(\mathrm{H}_{2} \mathrm{O}, \mathrm{MeOH}\right.$, acetone) to give fractions (frs.) $1-3$. Fraction 2 (10.1 g) was subjected to Chromatorex NH column chromatography [Fuji Silysia Chemical Co., Ltd., $\mathrm{CHCl}_{3}-\mathrm{MeOH}-\mathrm{H}_{2} \mathrm{O}(10: 2: 0.1,8: 2: 0.2,7: 3: 0.5,6: 4: 1,0: 1: 0), 50 \%$ $\mathrm{MeOH}, 40 \% \mathrm{MeOH}, 30 \% \mathrm{MeOH}, 20 \% \mathrm{MeOH}]$ to afford frs. 4-12. Fraction $9(2117 \mathrm{mg})$ was recrystallized from $\mathrm{MeOH}$ to give $3(155 \mathrm{mg})$. Chromatography of fr. $10(673 \mathrm{mg})$ on silica gel [Merck. Art $9385, \mathrm{CHCl}_{3}-$ $\left.\mathrm{MeOH}-\mathrm{H}_{2} \mathrm{O}(10: 2: 0.1,8: 2: 0.2,7: 3: 0.5,6: 4: 1)\right]$ furnished fr. 13 , fr. 14 and $4(52 \mathrm{mg})$. Fraction $13(173 \mathrm{mg})$ and fr. $14(173 \mathrm{mg})$ were each subjected to HPLC (column, Cosmosil 5C18 AR-II, Nacalai Tesque, Inc., $250 \mathrm{~mm} \times 20 \mathrm{~mm}$ i.d.; $60 \% \mathrm{MeOH})$ to furnish $1(11 \mathrm{mg})$ and $5(9 \mathrm{mg})$ from fr. 13 and 2 (11 mg) from fr. 14 .

1: Amorphous powder. $[\alpha]_{\mathrm{D}}^{24}-56.7^{\circ}(c=0.9$, pyridine). Negative FABMS $m / z: 1254[\mathrm{M}-\mathrm{H}]^{-}$. Positive FAB-MS $m / z: 1278[\mathrm{M}+\mathrm{Na}]^{+}$. HR positive FAB-MS $m / z$ : $1278.5756[\mathrm{M}+\mathrm{Na}]^{+}$(Calcd for $\mathrm{C}_{57} \mathrm{H}_{93} \mathrm{NO}_{29} \mathrm{Na}$ : 1278.5730). ${ }^{1} \mathrm{H}-\mathrm{NMR}$ (in pyridine- $\left.d_{5}, 500 \mathrm{MHz}\right) \delta: 5.58(1 \mathrm{H}, \mathrm{d}, J=7.0 \mathrm{~Hz}$, H-1 of Glc $), 5.25(1 \mathrm{H}, \mathrm{d}, J=8.0 \mathrm{~Hz}, \mathrm{H}-1$ of Xyl), $5.21(1 \mathrm{H}, \mathrm{d}, J=8.0 \mathrm{~Hz}, \mathrm{H}-$ 1 of Glc), $4.90(1 \mathrm{H}, \mathrm{d}, J=8.0 \mathrm{~Hz}, \mathrm{H}-1$ of Gal $), 4.83(1 \mathrm{H}, \mathrm{d}, J=8.0 \mathrm{~Hz}, \mathrm{H}-1$ of $\left.\mathrm{Glc}^{\prime \prime}\right), 4.67$ (1H, m, H-16), 3.84 (1H, dd, $J=9.0,9.0 \mathrm{~Hz}, \mathrm{H}-4$ of Glc), 3.68 $(1 \mathrm{H}, \mathrm{dd}, J=10.5,10.5 \mathrm{~Hz}, \mathrm{H}-5$ of Xyl), $3.59(1 \mathrm{H}, \mathrm{dd}, J=6.0,10.0 \mathrm{~Hz}, \mathrm{Hb}-$ 27), $3.46(1 \mathrm{H}, \mathrm{dd}, J=11.0,18.5 \mathrm{~Hz}, \mathrm{Hb}-26), 3.22\left(3 \mathrm{H}, \mathrm{s}, \mathrm{OCH}_{3}\right), 2.51(1 \mathrm{H}$, br d, $J=13.5 \mathrm{~Hz}, \mathrm{Ha}-24), 1.94(1 \mathrm{H}, \mathrm{d}, J=5.0 \mathrm{~Hz}, \mathrm{H}-17), 1.72\left(3 \mathrm{H}, \mathrm{s}, \mathrm{H}_{3}-21\right)$, $0.81\left(3 \mathrm{H}, \mathrm{s}, \mathrm{H}_{3}-18\right), 0.65\left(3 \mathrm{H}, \mathrm{s}, \mathrm{H}_{3}-19\right) .{ }^{13} \mathrm{C}-\mathrm{NMR}$ data: see Table 1.

2: Amorphous powder. $[\alpha]_{\mathrm{D}}^{24}-20.7^{\circ}(c=1.0$, pyridine $)$. Negative FABMS $m / z: 1270[\mathrm{M}-\mathrm{H}]^{-}$. Positive FAB-MS $m / z: 1294[\mathrm{M}+\mathrm{Na}]^{+}$. HR positive FAB-MS $m / z$ : $1294.5677[\mathrm{M}+\mathrm{Na}]^{+}\left(\mathrm{Calcd}\right.$ for $\mathrm{C}_{57} \mathrm{H}_{93} \mathrm{NO}_{30} \mathrm{Na}$ : 1294.5680). ${ }^{1} \mathrm{H}-\mathrm{NMR}$ (in pyridine- $\left.d_{5}, 500 \mathrm{MHz}\right) \delta: 8.93(1 \mathrm{H}, \mathrm{s}, \mathrm{NH}), 5.58$ $(1 \mathrm{H}, \mathrm{d}, J=7.0 \mathrm{~Hz}, \mathrm{H}-1$ of Glc' $), 5.45(1 \mathrm{H}, \mathrm{ddd}, J=7.5,7.5,7.5 \mathrm{~Hz}, \mathrm{H}-16)$, $5.25(1 \mathrm{H}, \mathrm{d}, J=7.5 \mathrm{~Hz}, \mathrm{H}-1$ of Xyl), $5.21(1 \mathrm{H}, \mathrm{d}, J=8.0 \mathrm{~Hz}, \mathrm{H}-1$ of Glc), $4.90(1 \mathrm{H}, \mathrm{d}, J=8.0 \mathrm{~Hz}, \mathrm{H}-1$ of Gal $), 4.87\left(1 \mathrm{H}, \mathrm{d}, J=8.0 \mathrm{~Hz}, \mathrm{H}-1\right.$ of Glc $\left.{ }^{\prime \prime}\right)$, $4.70(1 \mathrm{H}, \mathrm{dd}, J=9.5,9.5 \mathrm{~Hz}, \mathrm{Ha}-6$ of Gal $), 3.84(1 \mathrm{H}, \mathrm{dd}, J=9.0,9.0 \mathrm{~Hz}, \mathrm{H}-4$ of Gal), ca. $3.70(1 \mathrm{H}, \mathrm{Hb}-27), c a .3 .48(1 \mathrm{H}, \mathrm{Ha}-26), 3.46\left(3 \mathrm{H}, \mathrm{s}, \mathrm{OCH}_{3}\right)$, $3.22(1 \mathrm{H}, \mathrm{dd}, J=11.0,11.0 \mathrm{~Hz}, \mathrm{Hb}-26), 2.59(1 \mathrm{H}, \mathrm{m}, \mathrm{H}-25), 2.51(1 \mathrm{H}, \mathrm{d}$, $J=7.5 \mathrm{~Hz}, \mathrm{H}-17), 2.48(1 \mathrm{H}, \mathrm{brd}, J=12.5 \mathrm{~Hz}, \mathrm{Ha}-24), 2.42\left(3 \mathrm{H}, \mathrm{s}, \mathrm{H}_{3}-21\right)$, $2.20(1 \mathrm{H}, \mathrm{m}, \mathrm{H}-15), 1.88(1 \mathrm{H}, \mathrm{dd}, J=12.5,12.5 \mathrm{~Hz}, \mathrm{Hb}-24), 1.79(1 \mathrm{H}, \mathrm{br}$, $J=11.0 \mathrm{~Hz}, \mathrm{Ha}-4), 1.59$ (1H, dddd, $J=3.5,12.0,12.0,12.0 \mathrm{~Hz}, \mathrm{Hb}-2), 1.32$ $\left(3 \mathrm{H}, \mathrm{s}, \mathrm{H}_{3}-18\right), 1.01(1 \mathrm{H}$, ddd, $J=3.5,12.0,12.0 \mathrm{~Hz}, \mathrm{Hb}-12), 0.88(1 \mathrm{H}, \mathrm{m}$, $\mathrm{H}-5), 0.78$ (1H, m, Hb-1), $0.64\left(3 \mathrm{H}, \mathrm{s}, \mathrm{H}_{3}-19\right), 0.49$ (1H, dd, $J=9.5,9.5 \mathrm{~Hz}$, H-9). ${ }^{13}$ C-NMR data: see Table 1.

Acknowledgments We express our appreciation to Mr. K. Takeda and Mr. T. Iriguchi of Kumamoto University for their measurement of the NMR and MS spectra. This study was supported in part by the General Research Organization of Tokai University.

\section{References}

1) Fujiwara Y., Yahara S., Ikeda T., Ono M., Nohara T., Chem. Pharm. Bull., 51, 234-235 (2003).

2) Fujiwara Y., Takai A., Uehara Y., Ikeda T., Okawa M., Yamauchi K., Ono M., Yoshimitsu H., Nohara T., Tetrahedron, 60, 4915-4920 (2004).

3) Fujiwara Y., Yoshizaki M., Matsushita S., Yahara S., Abe E., Ikeda T., Ono M., Nohara T., Chem. Pharm. Bull., 53, 584-585 (2005).

4) Yahara S., Uda N., Yoshio E., Yae E., J. Nat. Prod., 67, 500-502 (2004).

5) Nagaoka T., Yoshihara T., Ohra J., Sakamura S., Phytochemistry, 34, 1153-1157 (1993).

6) Yoshihara T., Nagaoka T., Ohra J., Sakamura S., Phytochemistry, 27, 3982-3984 (1988).

7) Yokosuka A., Mimaki Y., Sashida Y., Nat. Med., 56, 208-211 (2002).

8) Ono M., Yamamoto M., Yanaka T., Ito Y., Nohara T., Chem. Pharm. Bull., 49, 82-86 (2001). 